\title{
COBERTURA VERDE: UM USO SUSTENTÁVEL NA CONSTRUÇÃO CIVIL
}

\section{GREEN ROOF: SUSTAINABLE USE IN CONSTRUCTION}

\author{
Débora Pedroso Righi, M.Sc (UFRGS) \\ Lucas Guilherme Köhler, Eng. (UNIPAMPA) \\ Rogério Cattelan Antocheves de Lima, Dr. (UFSM) \\ Almir Barros da S. Santos Neto, Dr. (UFSM) \\ Gihad Mohamad, Dr. (UFSM)
}

\author{
Palavras Chave \\ Sustentabilidade; Meio Ambiente; Construção Civil; Telhado Verde
}

\author{
Key Words \\ Sustainable; Environment; Building Construction; Green Green Roof
}

\section{RESUMO}

O conceito de desenvolvimento sustentável é discutido desde a década de 80 , esse conceito tem invadido as mais diversas áreas do conhecimento e setores da economia, principalmente na construção civil. A construção civil é uma das principais fontes de economia mundial, sendo responsável por $63 \%$ da formação bruta de capital fixo no Brasil. Apesar da sua indiscutível importância para o desenvolvimento do país, a construção civil é apontada como uma das indústrias que mais impactam o meio ambiente. Para mudar esse aspecto à construção civil vem utilizando novos materiais que produzam o menor impacto possível ao meio ambiente e contribuam para o conforto térmico ou a redução do consumo de energia, inúmeros exemplos de novos materiais e tecnologias vem sendo empregados com essa finalidade.

Um exemplo de como a sustentabilidade pode trazer benefícios ao meio ambiente e a seus habitantes é o uso de coberturas verdes, estas coberturas caracterizam-se pela utilização de vegetação como cobertura de estruturas de qualquer porte. Esse tipo de construção proporciona o combate às ilhas de calor urbano, absorvendo gases do efeito estufa emitidos por veículos e melhorando a qualidade do ar nos centros urbanos. Este trabalho tem como objetivo apresentar a viabilidade da aplicação dos telhados verdes na construção civil. São mostrados também conceitos, propriedades, método de execução, vantagens, desvantagens da utilização do mesmo. Ao final do trabalho são extraídas algumas considerações, conclusões e apresentadas algumas aplicações no Brasil sobre o uso de telhados verdes.

\section{ABSTRACT}

The concept of sustainable development is discussed since the 80s, the concept has invaded the most diverse areas of knowledge and sectors of the economy, especially in construction. The construction industry is a major source of the world economy, accounting for $63 \%$ of gross fixed capital formation in Brazil. Despite its undoubted importance for the development of the country, construction is considered one of the industries that most impact the environment. To change this aspect of the construction has been using new materials that produce the least possible impact to the environment and contribute to thermal comfort and reducing energy consumption, numerous examples of new materials and technologies are being used for this purpose.

An example of how sustainability can bring benefits to the environment and its inhabitants is the use of green roofs, these roofs are characterized by the use of vegetation as any sized structures coverage. This type of construction provides combating urban heat islands, absorbing greenhouse gases emitted by vehicles and improving air quality in urban centers. This paper aims to present the feasibility of the implementation of green roofs in construction. They are also shown concepts, properties, method of implementation, advantages, disadvantages of using it. At the end of the work are drawn from some considerations, conclusions and presented some applications in Brazil on the use of green roofs. 


\section{INTRODUÇÃO}

O tema sustentabilidade tem apresentado crescente interesse entre pesquisadores acadêmicos. Sua importância se deve principalmente à atenção despertada face às mudanças climáticas causadas pela ação predatória do homem no meio ambiente causando uma emergência planetária (BACHA et al., 2010).

O conceito de sustentabilidade tem invadido as mais diversas áreas do conhecimento e setores da economia. $\mathrm{Na}$ construção civil, este tema tem ganhado maior destaque nos últimos anos, por ser responsável por consumir $2 / 3$ da madeira natural e cerca de $50 \%$ dos recursos naturais do planeta, sendo grande parte de recursos não renováveis e a fabricação de cimento ser responsável por $8 \%$ do total de emissões de gases, vem-se mudando a forma de construir, procurando adequar à sustentabilidade na construção civil (ANTUNES, 2009). O que proporciona um grande entrave para a criação da visão sustentável é a enorme dificuldade em relação aos custos, ainda elevados, de determinados elementos que permitem o enquadramento do empreendimento no conceito de sustentabilidade.

Desde meados da década de 2000, a maior parte da população tem se concentrado nas áreas urbanas, para atender essa demanda populacional foram construídas áreas de concreto como casas, edifícios, calçadas diminuindo cada vez mais as áreas verdes. Na busca para suprir a falta de áreas verdes nas grandes cidades um novo conceito tem ganhado maior destaque, conhecidos popularmente, como telhados verdes, é uma ideia sustentável que tem tudo para ajudar a balancear o concreto e a vegetação.

O conceito sobre telhados verdes não é algo inovador, sabe que a primeira obra que adotou esse método foi construída 605 a.C chamada de Os Jardins Suspensos, uma das Sete Maravilhas do Mundo Antigo, esta obra foi construída com um terraço em cima do outro e eram irrigados pela água bombeada do rio Eufrates. Nesses terraços estavam plantadas árvores e flores tropicais e alamedas de altas palmeiras (PEREIRA, 2015).

A ideia é transformar os "telhados verdes" em pequenos pulmões das grandes cidades criando corredores que facilitem a circulação atmosférica, melhore o clima, reduza o consumo de energia, provoque um decréscimo no uso do ar condicionado em regiões quentes e isolem o frio em regiões com invernos rigorosos, já que sob um telhado coberto de vegetação, as baixas temperaturas demoram mais para chegar aos espaços internos, um problema de pouca importância para o Brasil, mas essencial para países europeus e regiões montanhosas do México e Bolívia.

Outro aspecto interessante é que nas regiões de chuva intensa, as áreas naturais podem reter de $15 \%$ a $70 \%$ do volume de águas pluviais, prevenindo a ocorrência de enchentes. Estudos demonstram que para uma cobertura verde leve de $100 \mathrm{~m}^{2}$, cerca de 1400 litros de água de chuva deixam de ser enviados para a rede pública. Os telhados verdes reduzem também os efeitos danosos dos raios ultravioletas, os extremos de temperatura e os efeitos do vento, vez que nesses telhados a temperatura não passa de $25^{\circ} \mathrm{C}$ contra $60^{\circ} \mathrm{C}$ dos telhados convencionais.

\section{SUSTENTABILIDADE}

Segundo o Ministério do Meio Ambiente Brasileiro o setor da construção civil tem papel fundamental para a realização dos objetivos globais do desenvolvimento sustentável. O Conselho Internacional da Construção - ClB aponta a indústria da construção como o setor de atividades humanas que mais consome recursos naturais e utiliza energia de forma intensiva, gerando consideráveis impactos ambientais. Estima-se que mais de $50 \%$ dos resíduos sólidos gerados pelo conjunto das atividades humanas sejam provenientes da construção. Tais aspectos ambientais, somados à qualidade de vida que o ambiente construído proporciona, sintetizam as relações entre construção e meio ambiente.

No Brasil, uma das maiores dificuldades para implementação da sustentabilidade no setor da construção civil, diz respeito à falta de iniciativas públicas de infraestrutura, o que acaba elevando, e muito, o custo de uma casa ou um prédio sustentável.

No mundo já existem certificações voltadas para construções sustentáveis, como a americana LEED (Leadership in Energy and Environment Design), mais famosa, e a francesa HQE (Haute Qualité Environment). Há ainda, a certificação AQUA (Alta Qualidade Ambiental), baseada na $H Q E$, e que vem a ser o primeiro referencial técnico para construções sustentáveis. De modo geral, essas certificações se fundamentam no princípio de eficiência energética, uso racional de água, coleta seletiva, qualidade ambiental interna da edificação (ANTUNES, 2009).

Além de uma certificação brasileira, foi criado em agosto de 2007 o CBCS, Conselho Brasileiro de Construção Sustentável, que tem como objetivo induzir o setor da construção a utilizar práticas mais sustentáveis, melhorando a qualidade de vida dos usuários, dos trabalhadores e do entorno das edificações. O CBDS é composto por diversos comitês que tratam de assuntos específicos relacionados à sustentabilidade no setor, como materiais e finanças (além dos óbvios, água e energia).

Segundo Antunes (2009) existem agências reguladoras governamentais que estabelecem e fiscalizam os empreendimentos dentro do conceito de sustentabilidade. Trabalham, juntamente com a iniciativa privada, para que 
o impacto causado por esses empreendimentos e pelos resíduos gerados nas obras de construção civil e no funcionamento posterior do projeto sejam os mínimos possíveis. É muito importante que as próprias agências e a população em geral sejam capazes de dar preferência aos empreendimentos que sigam as práticas e determinações da aplicação do conceito de sustentabilidade. Assim, criam-se as forças necessárias para reunir condições favoráveis para a criação, o fomento e a consolidação de uma visão empresarial mais consciente e atenta para as questões ligadas ao meio ambiente e ao impacto de seus empreendimentos nele.

\section{COBERTURAS VERDES}

\subsection{Contextualização}

Um planejamento urbanístico sustentável de uma cidade pode ser beneficiado por uma série de soluções pautadas na economia de energia, racionalidade do consumo, redução das emissões de poluentes e na manutenção do ciclo hidrológico local (OLIVEIRA, 2009).

Os telhados verdes, ecotelhados, coberturas vivas ou coberturas verdes são estruturas que se caracterizam pela aplicação de cobertura vegetal nas edificações com impermeabilização e drenagem adequadas. Os telhados verdes são estruturas que se caracterizam pela aplicação de cobertura vegetal nas edificações. Consistem basicamente em uma camada da vegetação, uma camada de substrato (onde a água é retida e a vegetação é escorada) e uma camada de drenagem responsável pela retirada da água adicional.

Os telhados verdes representam uma alternativa que compõem uma mudança de paradigmas projetuais, oferecendo a possibilidade de utilização de materiais locais, apresentando benefícios térmicos e acústicos, ganhos na umidificação do ar, suavização de altas temperaturas e filtragem de material particulado e gases nocivos à saúde humana (KREBS, 2005).

Segundo Antunes (2009) as plantas mais utilizadas são as xerófitas, plantas que vivem em região com pouca água, similar aos cactos, que economizam água e podem sobreviver em condições adversas em cima do telhado. Estas espécies não necessitam de podas e exigem pouca irrigação.

O telhado verde não funciona como uma estrutura independente, sendo necessária a execução de uma sub-base ou sub-telhado, como apoio para as telhas ecológicas. Este sub-telhado é igual ao telhado convencional que pode ser de fibrocimento, telha metálica, laje de concreto impermeabilizada, telha cerâmica e/ou geomembrana de PEAD (Polietileno de Alta Densidade).

Todo o processo desde a execução até a manutenção da cobertura verde é realizado com máxima preocupação na impermeabilização da laje, na drenagem pluvial, e no meio ambiente. Todas essas preocupações são levadas em consideração para garantir o bem-estar, tanto das pessoas que habitam a residência, quanto das pessoas que convivem nesta mesma sociedade, pois todos fazem parte do mesmo ecossistema.

\subsection{Benefícios do uso}

Um dos mais importantes benefícios das coberturas verdes é a contribuição para a estabilização do clima ao seu entorno, servindo de isolante térmico, trazendo benefícios para os usuários e economia de energia, pois reduz gastos com a climatização e os efeitos das "ilhas de calor urbano". Um estudo conduzido pelo Environment Canadá Found demonstrou uma redução de $26 \%$ nas necessidades de resfriamento artificial nos dias quentes e uma redução de $26 \%$ nas perdas de calor nos meses de inverno (PIERGILI, 2007).

Em termos de termoacústicas há uma melhora na edificação, tanto no inverno como no verão. Estudos de bioclimatismo indicam que, com o uso de coberturas vivas, seja possível melhorar em $30 \%$ as condições acústicas no interior da edificação, sem recorrer a sistemas de climatização ou ar-condicionado artificiais.

$O$ teto verde também mantém a umidade relativa do ar constante no entorno da edificação, forma um microclima e purifica a atmosfera no entorno da edificação, formando um microecossistema. Contribui no combate ao efeito estufa, aumentando o 'seqüestro' (retirada) de carbono da atmosfera e ao mesmo tempo traz mais harmonia, bem estar e beleza para os moradores e/ou ocupantes da edificação. É também um excelente atrativo para pontos comerciais, tornando-os mais visíveis, mesmo quando distantes de locais estratégicos.

As plantas e a terra do telhado verde funcionam como um filtro natural da água, que pode ser armazenada ainda mais limpa, para depois ser usada na irrigação do jardim, nas bacias sanitárias, no chuveiro e, em regiões mais áridas, até para cozinhar e beber.

Os efeitos dos telhados verdes no escoamento superficial consistem em: uma redução no volume e na velocidade da água escoada, devido a capacidade de retenção das plantas e atraso no pico do escoamento, pois ocorre absorção da água no telhado verde (CASTRO 2011).

\section{MÉTODOS DE EXECUÇÃO}

\subsection{Impermeabilização}

O processo de impermeabilização é o mais importante para uma excelente execução dos telhados verdes. Este 
processo se caracteriza pela aplicação de uma manta PEAD ou manta asfáltica anti-raízes sobre o sub-telhado.

As geomembranas são mantas laminadas flexíveis de polietileno de alta densidade, são desenvolvidas para esta aplicação especifica, asseguram uma alta resistência física a ruptura por tração e química a ácidos, bases, sais e solventes orgânicos e inorgânicos.

As geomembranas oferecem alto grau de segurança de impermeabilidade. Suas junções são realizadas através de soldagem eletrônica (Termo-Fusão), que podem passar pelos mais rigorosos testes de qualidade, durabilidade e resistência. (SOMA, 2009).

\subsection{Tipos de sistemas com sua execução}

Segundo Souza (2009) visando a melhor adaptação do teIhado verde aos diversos tipos de cobertura existentes, bem como aos diferentes tipos de plantas e regimes hidrológicos, a Ecotelhado, uma empresa de Porto Alegre/RS, desenvolveu três tipos de sistemas de utilização da ecotelha. São os sistemas: Modular, Alveolar e Laminado. Estes sistemas são descritos conforme execução da empresa Ecotelhado.

Porém todos os sistemas seguem, previamente, o mesmo processo de impermeabilização que se caracteriza pela aplicação de uma manta PEAD ou manta asfáltica anti-raízes que já foi mencionado anteriormente, seguido de uma membrana de retenção de nutrientes ou substrato, e logo em seguida a colocação dos módulos com o substrato e as plantas já germinadas conforme a Figura 01.

Figura 01 - Seção do Telhado com suas respectivas camadas.

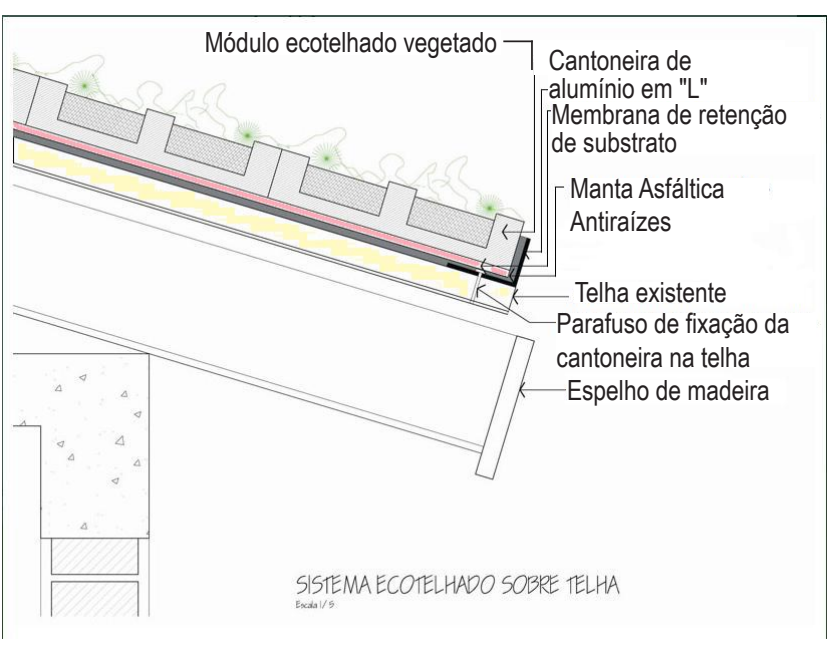

Fonte: www.ecotelhado.com.br

Outro ponto importante é o transpasse das membranas que ajudam a prevenir possíveis infiltrações. Este transpasse varia de acordo com o tipo da membrana devendo seguir os seguintes padrões nas emendas: membrana anti-raízes, transpasse de $50 \mathrm{~cm}$; membrana de retenção de nutrientes, transpasse de $5 \mathrm{~cm}$; membrana filtrante, transpasse de $10 \mathrm{~cm}$.

Em algumas ocasiões se faz necessário à substituição das telhas cerâmicas por tabuado de madeira, isso somente ocorrerá se as mesmas se encontrarem velhas e quebradiças. É recomendado o uso de tábuas por serem mais baratas do que as chapas compensadas e por serem bastante resistentes.

\subsubsection{Sistema modular}

É o sistema mais utilizado, composto por módulos já vegetados dispostos lado a lado e colocados sobre a membrana anti-raízes. Este sistema permite a aplicação do ecotelhado praticamente sobre qualquer tipo de teIhado ou laje, inclinados ou não e pesa cerca de $50 \mathrm{~kg} / \mathrm{m}^{2}$. O telhado vivo se constitui, preferencialmente, de uma planta adaptada a solos rasos, resistentes à estiagem, de baixa manutenção como os seduns e outras suculentas. Neste sistema é vetada a utilização de grama devido à alta exigência de água.

Figura 02 - (a) colocação da membrana anti-raízes; (b) colocação da membrana de retenção de nutrientes e módulos Ecotelha; (c) detaIhe do dreno; (d) acabamentos finais.

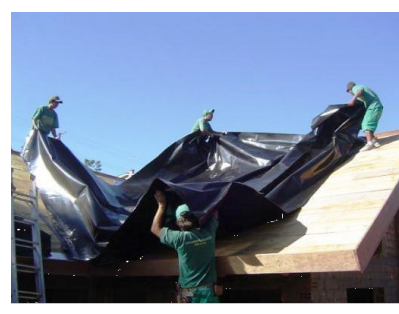

(a)

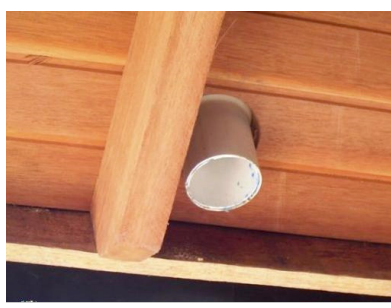

(c)

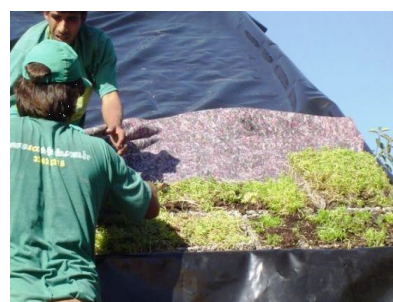

(b)

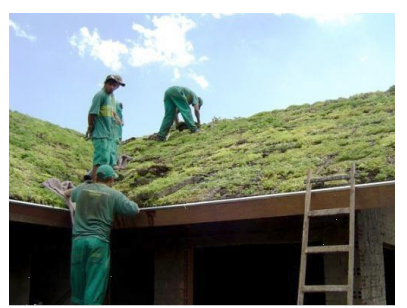

(d)
Fonte: www.ecotelhado.com.br

Após a limpeza do sub-telhado onde é aplicada a cobertura realiza-se a colocação da membrana anti-raízes (Figura 02 (a)). Neste exemplo é possível visualizar a aplicação da membrana anti-raízes sem emendas, pois o telhado possui dimensões pequenas. Na Figura 02 (b) vê-se o detalhe da colocação dos módulos. Na primeira fiada os módulos são colocados na horizontal enquanto que o primeiro módulo da segunda fiada é colocado na posição vertical para garantir a alternância e consequentemente o maior travamento das demais fiadas, em um sistema que é similar ao travamento de uma alvenaria de blocos cerâmicos. 
Na Figura 02 (c) é possível visualizar o detalhe do dreno. Pode ser contraditório drenar a água visto que as plantas devem resistir a longos períodos de estiagem, porém o dreno se faz necessário para impedir o acúmulo da água e posteriormente a morte das plantas por afogamento. $O$ que garante a hidratação do sistema modular é a água retida nos módulos da ecotelha e no substrato, além das plantas serem típicas de regiões desérticas, ou seja, pouco consumidoras de água. Os arremates na junção das quedas do telhado são feitos cortando-se os módulos da ecotelha e os acabamentos finais consistiram em colocar o perfil " $U$ " seguido da arrumação da vegetação (Figura 02 (d)).

\subsubsection{Sistema alveolar}

Este sistema possui o mesmo princípio do sistema modular, o que difere é que o mesmo recebe uma membrana alveolar que se caracteriza por ser uma placa flexível feita de garrafa pet reciclada com dimensões $1,20 \times 0,95 \mathrm{~m}$ por $2 \mathrm{~cm}$ de espessura com cavidades alveolares que auxiliam na retenção da água. Acima da membrana alveolar este sistema recebe ainda, uma membrana filtrante que é um tecido não tecido de alta permeabilidade que serve como proteção contra sujeiras nos alvéolos como ilustrado na Figura 03.

Figura 03 - Camadas do sistema alveolar. 1-manta antiraízes; 2-membrana alveolar; 3-membrana filtrante; 4-módulo ecotelha; 5-substrato leve $(1 \mathrm{~cm}$ ou mais).

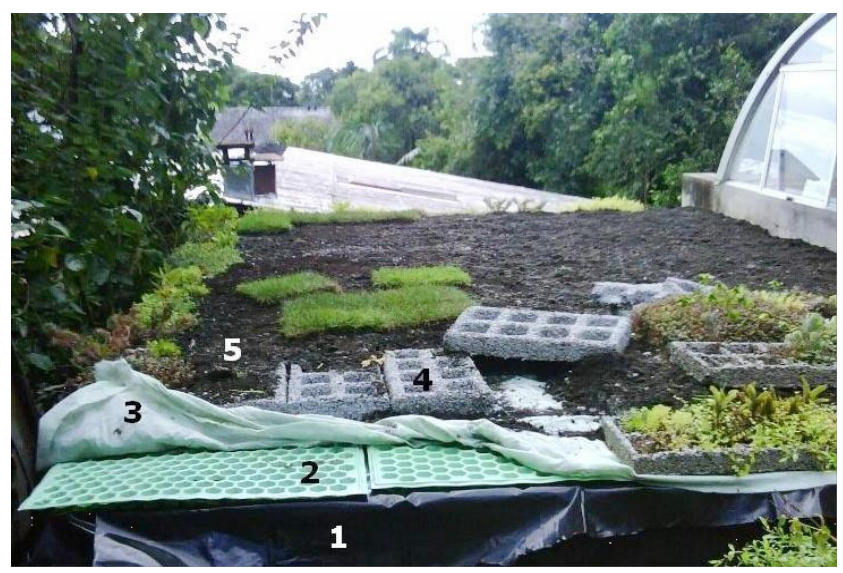

Fonte: www.ecotelhado.com.br

Neste sistema é permitido o uso de maior variedade de plantas, como os arbustos, além de espécies nativas da região. Um exemplo dessas plantas são as gramas, que só sobrevivem porque os alvéolos retém uma quantidade maior de água. $\mathrm{O}$ peso saturado deste sistema varia entre 60 a $80 \mathrm{~kg} / \mathrm{m}^{2}$ e cada 10 litros $/ \mathrm{m}^{2}$ corresponde a $1 \mathrm{~cm}$ de altura da lâmina d'água.

Existe ainda a possibilidade de se utilizar o sistema alveolar em telhados inclinados, porém a efetividade de suas características é inversamente proporcional à inclinação do telhado. Ou seja, quanto mais inclinado o telhado, menores serão os efeitos acima mencionados. Na Figura 04 (a) (b) é possível visualizar a colocação da membrana alveolar, sendo cortada quando necessário como para fazer o arremate na chaminé. Na Figura 04 (c) pode-se ver a colocação da membrana filtrante e na Figura 04 (d) uma vista geral da instalação em uma residência.

Figura 04 - (a) colocação da membrana alveolar; (b) arremate da membrana alveolar; (c) colocação da membrana filtrante; (d) vista geral da instalação.

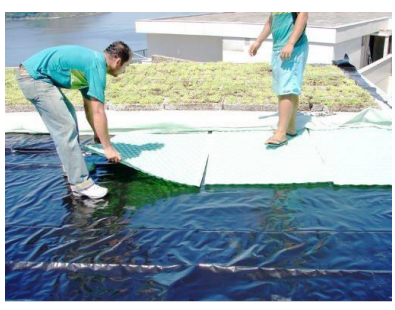

(a)

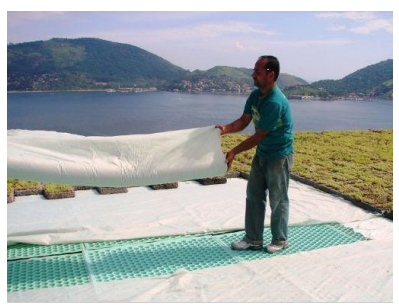

(c)

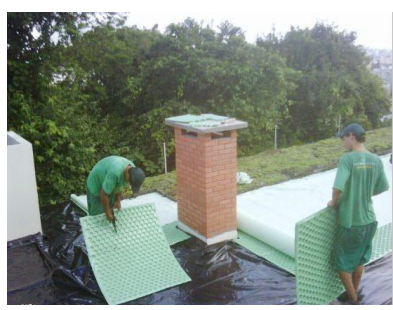

(b)

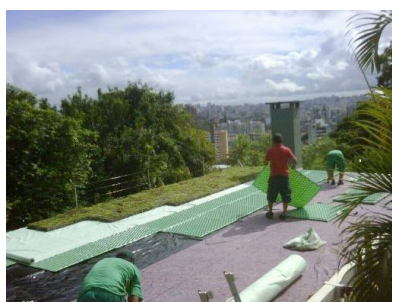

(d)
Fonte: www.ecotelhado.com.br

\subsubsection{Seção laminar}

O sistema laminar se caracteriza por utilizar uma lâmina d'água, regulada por um "ladrão", sob um piso elevado feito de módulos de sustentação, que são nada mais do que os módulos de ecotelha "virados de cabeça para baixo". Este sistema só pode ser instalado sobre lajes planas sem declividade para ser possível à formação da lâmina. No caso de caimento, devem ser feitas subdivisões para manter o nível da água. Esta lâmina garante um suprimento de até $40 \mathrm{l} / \mathrm{m}^{2}$ (4cm de altura) e exemplifica os benefícios de retenção pluvial e conforto térmico, portanto é ideal para o teIhado de grama podendo-se, ainda, ampliar a variedade de forrações, inclusive permitindo a utilização de pequenos arbustos. O peso total do sistema é de $120 \mathrm{~kg} / \mathrm{m}^{2}$ já saturado, podendo variar de acordo com o tamanho da vegetação.

Este sistema permite, também, a purificação de águas cinzas - águas que são derivadas do uso doméstico ou comercial exclusivamente dos chuveiros, lavatórios de banheiro, banheiras, tanques e máquinas de lavar roupas com posterior reutilização nos vasos sanitários do prédio.

Na Figura 05 pode-se ver um exemplo teste do sistema laminar feito na sede da Ecotelhado. Depois da membrana anti-raízes foram colocados os módulos invertidos seguidos 
da membrana de retenção de nutrientes e do substrato onde foram colocadas as leivas de grama. Passados 30 dias de seca pôde-se ver que no sistema laminar a grama continuou verde enquanto que no lote testemunha ao lado ela ficou ressecada. Vale observar que o substrato neste sistema fica espalhado sobre a membrana de retenção, e não dentro dos módulos como nos sistemas modular e alveolar.

Figura 05 - (a) colocação do substrato leve fibroso; (b) colocação de leivas de grama; (c) detalhe do dreno lateral $4 \mathrm{~cm}$; (d) diferença entre o sistema laminar e o lote experimental após 30 dias de seca.

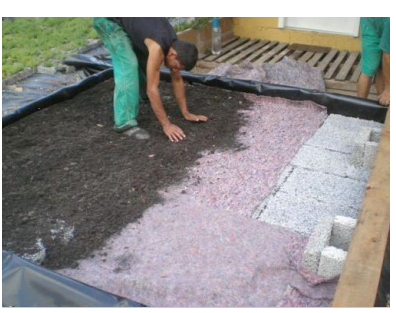

(a)

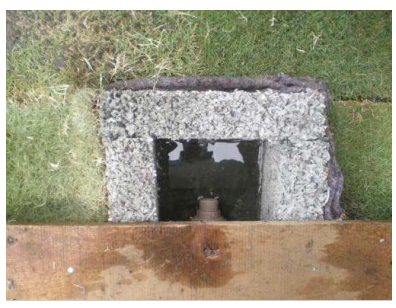

(c)

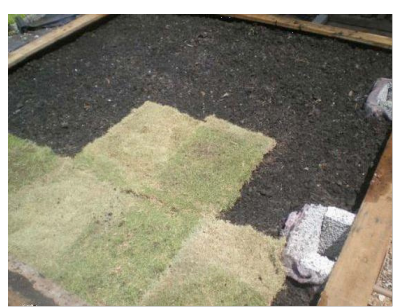

(b)

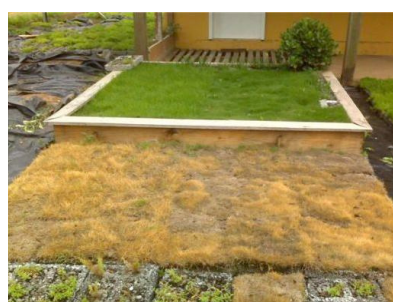

(d)
Fonte: www.ecotelhado.com.br

\section{VANTAGES E DESVANTAGENS}

Como vantagens as coberturas trazem vários benefícios como novas áreas verdes, menos gás carbônico devido ao sequestro do gás carbônico da atmosfera reduzindo a poluição e o efeito estufa. Servem como isolamento térmico, as condições ambientais de dentro de uma construção ficam mais amenas quando possuem um telhado verde, traz como vantagem também a limpeza devido a telhados normais necessitarem de limpeza com mais frequência, geralmente essa limpeza demanda recursos financeiros com o uso do hidrojateamento.

Mas não se pode deixar de mencionar que os telhados verdes também necessitam de cuidados, apesar de não precisarem de limpeza como um telhado convencional, os mesmos requerem cuidados que podem ser considerados benéficos, uma vez que o contato com a terra e com vegetais pode funcionar como terapia anti-estresse.

Os telhados verdes proporcionam uma melhora na acústica, impedindo a entrada de sons em determinadas frequências e a umidade também melhora com a utilização dos mesmos.

A evapotranspiração e a sombra produzidas pelas plantas ajudam a eliminar o efeito da Ilha de Calor Urbana criado pelo excesso de superfícies reflexivas e impermeáveis nas cidades e nos subúrbios. Como as Ilhas de Calor Urbanas elevam a temperatura em áreas urbanas e suburbanas, elas acabam aumentando a demanda por apareIhos de ar-condicionado e iniciam um ciclo de consumo de energia que contribui para o aquecimento global. Se os telhados ecológicos se tornarem uma iniciativa comum nas construções, as cidades podem reduzir os efeitos incômodos das Illhas de Calor Urbanas.

Porém, dentre algumas desvantagens, está o fato de que se o telhado verde não for bem cuidado ele pode atrair pragas urbanas como, por exemplo, o mosquito da dengue. $\mathrm{O}$ custo inicial de coberturas ecológicas muitas vezes afasta possíveis clientes. Como o telhado ecológico exige um trabalho profissional, análise estrutural cuidadosa e várias camadas e sistemas, acaba ficando muito "mais caros" do que telhados comuns.

Por enquanto, os benefícios econômicos de longo prazo já ultrapassam os custos iniciais. Como os telhados ecológicos protegem a membrana do telhado do clima severo e da radiação ultravioleta (UV), eles podem durar duas vezes mais do que os telhados tradicionais.

\section{APLICAÇÕES NO BRASIL}

No Brasil, apesar da pouca divulgação e do pouco conhecimento dos métodos de execução das coberturas verdes, é possível ver sua aplicação em alguns estados. A maior concentração dessa prática se encontra nas regiões sul e sudeste.

Na Figura 06 pode-se visualizar a Passarela Ecológica, que foi uma reforma realizada em uma antiga passarela, com uma parceria da prefeitura de São Paulo e o Unibanco, onde foram gastos $\mathrm{R} \$ 1.200 .000,00$ (um milhão e duzentos reais) para que, utilizando medidas sustentáveis, transformasse a passarela em uma passarela que impactasse o meio ambiente da menor maneira possível.

Os outros fatores sustentáveis utilizados nesta passarela foram: piso antiderrapante feito de borracha reciclada; uso de madeira plástica nos painéis laterais; elevador de deficientes feito de aparas de tubo de creme dental; a região redor da passarela recebeu piso permeável onde antes era cimentado, transformando o lugar numa praça com arbustos e árvores nativas.

A Figura 07 ilustra outro exemplo de telhado verde no Brasil, este foi realizado na Loja Fabricário em Porto Alegre, com a sua fachada antes e depois da execução do telhado verde. Na Figura 08, pode-se visualizar o ecotelhado na cobertura do Jornal Zero Hora, em Porto Alegre, realizado no mês de março de 2009. A área total de aplicação foi de $1.550 \mathrm{~m}^{2}$ que foi feita em 32 horas com 12 profissionais. Foram utilizados 6500 módulos ecotelhado, $1.674 \mathrm{~m}^{2}$ de 
membrana anti-raízes, 1.550 placas alveolares, $1600 \mathrm{~m}^{2}$ de membrana de retenção, 1.000 módulos maciços ecotelhado e 12.500 litros de substrato leve (ECOTELHADO, 2011).

A primeira escola ecológica do país foi inaugurada em maior de 2001 em um dos bairros mais carentes do Rio de Janeiro: Santa Cruz, zona oeste da cidade. O Colégio Estadual Erich Walter Heine foi projetado em forma de catavento para melhor ventilação, a escola possui telhado verde com vegetação que absorve o calor, em uma região em que a temperatura ultrapassa os 40 graus celsius no verão, e sistema de captação de água da chuva que é destinada posteriormente para as descargas dos banheiros, jardins e limpeza conforme Figura 09 (AGNOL et al., 2013).

Figura 06 - Passarela ecológica - São Paulo.

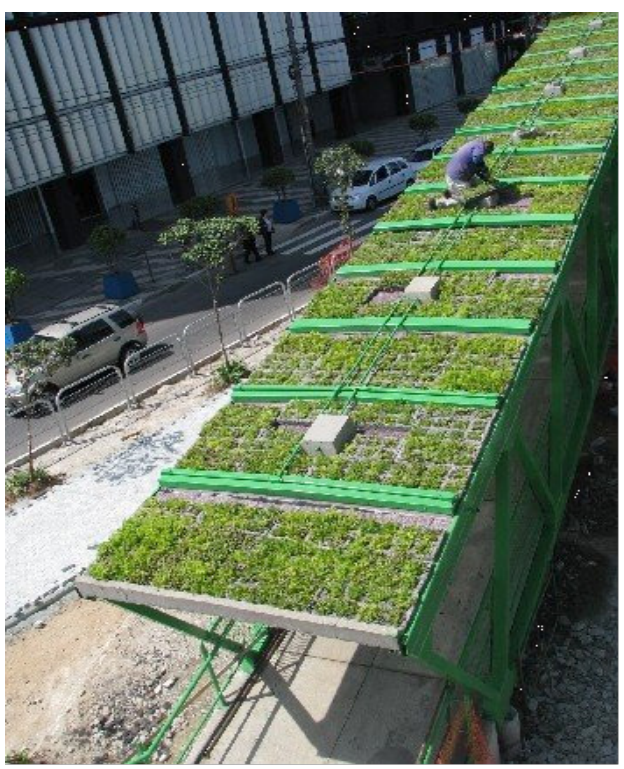

Fonte: www.ecotelhado.com.br

Figura 07 - Loja Fabricário em Porto Alegre (antes/depois).

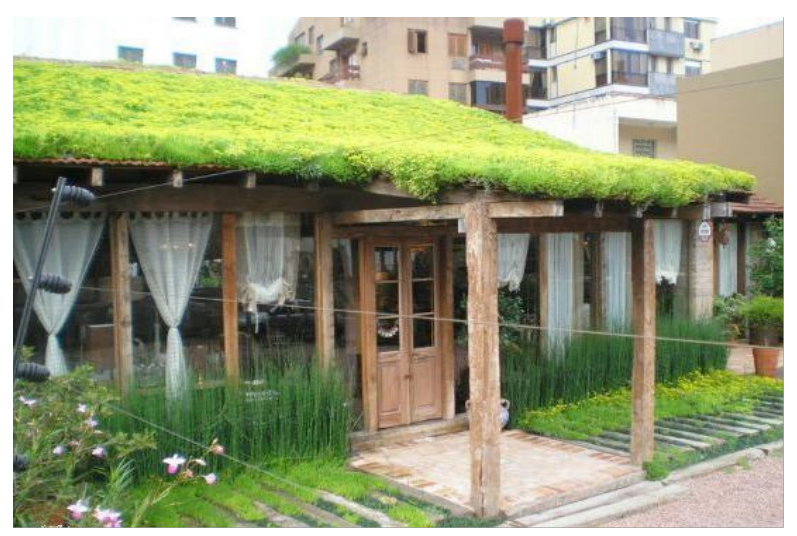

Fonte: www.ecotelhado.com.br

\section{CONCLUSÕES}

Como considerações finais, pode-se dizer que as coberturas verdes foram criadas como resposta a grande degradação que o meio ambiente vem sofrendo, no sentido de tentar reverter este quadro de poluição crônica que aflige a sociedade durante décadas.

Porém, a aplicação das coberturas verdes se encontra restrita nas regiões sul e sudeste, devido ao fato de encontrar barreiras na sua divulgação e no conservadorismo dos engenheiros pouco informados. Acredita-se estar contribuindo para a divulgação desta alternativa tecnológica através deste artigo, que cumpre este papel de forma didática com a qual foram demonstradas as qualidades pertinentes a uma cobertura verde e as suas respectivas restrições no que se diz respeito à impermeabilização adequada e mão de obra qualificada.

Mas a sua ampla gama de contribuições apresentadas, conferem ao sistema um efeito social na medida em que fornece à sociedade um modelo de cultura sustentável, que é uma alternativa a um mundo mais ecológico e menos devastador.

Espera-se que os casos demonstrados possam servir de exemplo para as construções futuras, enfatizando a importância da necessidade de ser feito em paralelo uma ampliação e aprofundamento no estudo das coberturas verdes.

Figura 08 - Parque Gráfico Do Jornal Zero Hora.

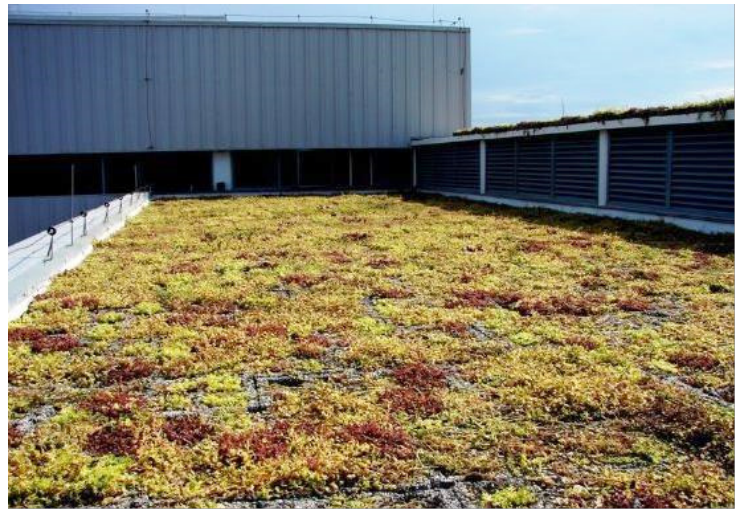

Fonte: www.ecotelhado.com.br

Figura 09 - Colégio Estadual Erich Walter Heine.

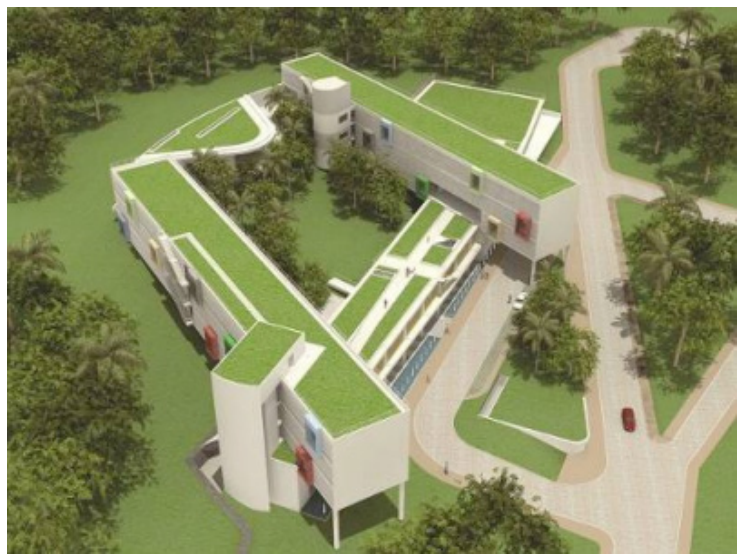

Fonte: www.ecotelhado.com.br 


\section{REFERÊNCIAS}

AGNOL, L.D., GATTERMANN, L.S., CASA, M.G.S., Sustentabilidade na arquitetura brasileira. Segundo Seminário Nacional de Construções Sustentáveis, Passo Fundo/RS, 2013.

ANTUNES, J., A sustentabilidade na construção civil. Disponível em: <http://www.administradores.com. br/artigos/economia-e-financas/a-sustentabilidade-na-construcao-civil/36112/>. Acesso dezembro de 2009.

BACHA, M.L., SANTOS, J., SCHAUN, A., Considerações teóricas sobre o conceito de sustentabilidade. VII Simpósio de Excelência em Gestão e Tecnologia, 2010.

CASTRO, A.,S., Uso de pavimentos permeáveis e coberturas verdes no controle quali-quantitativo do escoamento superficial urbano. Tese de Doutorado, Universidade Federal do Rio Grande do Sul, Porto Alegre, 2011.

ECOTELHADO. Disponível em <www.ecotelhado.com. br> Acesso em janeiro de 2011.

KREBS, L.F. Coberturas vivas extensivas: análise da utilização em projetos na região metropolitana de Porto Alegre e serra gaúcha. UniversidWade Federal do Rio Grande do Sul, Porto Alegre, 2005.

OLIVEIRA. E.W.N.de. Telhados verdes para habitações de interesse social: retenção das águas pluviais e conforto térmico. Universidade Estadual do Rio de Janeiro, Rio de Janeiro, 2009.

PEREIRA, C.D.O., Quando o telhado verde vira lei. Disponível em <http://caroldaemon.blogspot.com. br/2015/04/quando-o-telhado-verde-vira-lei.html>. Acesso em junho de 2015.

PIERGILI, A.V.P. Por que utilizar telhados verdes? 2007. Disponívelem:<http://sitiogralhaazul.net/dev15/index.php?option=com_content $\&$ view=article\&id=42:por-que-tilizar-telhados-verdes\&catid=30:design-ecolo>. Acesso em: maio de 2007.

SOMA, L. G. Estudo do Processo de Impermeabilização de Edifícios Residenciais. Programa de Conclusão de Curso, Universidade Anhembi Morumbi, São Paulo 2009.

SOUSA, C. G., O Processo Construtivo Das Coberturas Verdes E Suas Principais Características. Trabalho de Conclusão de Curso, maio de 2009. 